Article

\title{
Indigenous Perspectives on Water Security in Saskatchewan, Canada
}

\author{
Obadiah Awume, Robert Patrick * and Warrick Baijius (D) \\ Department of Geography and Planning, University of Saskatchewan, Saskatoon, SK S7N 5C5, Canada; \\ obadiahaa@gmail.com (O.A.); warrick.baijius@usask.ca (W.B.) \\ * Correspondence: robert.patrick@usask.ca
}

Received: 2 January 2020; Accepted: 11 March 2020; Published: 14 March 2020

\begin{abstract}
The term "water security" continues to gain traction in water resources literature with broad application to human health, water quality, and sustainability of water supply. These western science applications focus almost exclusively on the material value of water for human uses and activities. This paper offers voice to other interpretations of water security based on semi-structured interviews with Indigenous participants representing varied backgrounds and communities from Saskatchewan, a Canadian prairie province. The results indicate that water security from an Indigenous perspective embraces much more than the material value of water. Five themes emerged from this research that speak to a more holistic framing of water security to include water as a life form, water and the spirit world, women as water-keepers, water and human ethics, and water in Indigenous culture. This broader interpretation provides a more nuanced understanding of water security, which serves to enrich the water security narrative while educating western science.
\end{abstract}

Keywords: Saskatchewan; Canada; indigenous people; water governance; water security

"Traditional Knowledge will patiently wait for western science to catch up. It will take time." —Lee Crowchild, Tsuut'ina First Nation, Treaty 7, Alberta, Canada

\section{Introduction}

The concept of water security emerged in the 1990s and was used in relation to military security, food security, and environmental security [1]. After 2001, the number of publications containing the term "water security" increased across a wide range of disciplines, from engineering and agriculture to public health and water resources [2]. The focus on water security has shifted to include water quality, human health, water-related hazards, sustainable development, water supply, and ecological concerns. Water security, as presented in the literature, involves a balance between the protection of resources and the enhancement of livelihoods [3,4]. Determinants of water security include water availability for ecosystem services as well as acceptable quality and quantity for human uses [5]. Water security is presented in the literature as meeting short and long-term needs to enable access to sufficient water quality, at a fair price, for human health, safety, welfare, and productive capacity [6]. In addition, water security has been linked to the political, social, and economic power of people in society $[7,8]$. With a few notable exceptions [9-11], the literature is largely silent on the meaning of water security from an Indigenous perspective, a condition that has motivated this paper.

The inability to access affordable drinking water quality and quantity for many Indigenous communities in Canada is a persistent problem [12-14]. There is an on-going challenge in providing safe drinking water to most Indigenous communities in Canada, resulting in one in five of these communities being under a drinking water advisory at any one time $[15,16]$. The reason for the high number of contamination events is beyond the scope of this paper but includes the lack of community 
water distribution systems, inadequate technology, lack of federal funding, and land use activities that affect source water quality $[15,17,18]$.

In 2017, the federal agency Health Canada reported approximately 100 long-term drinking water advisories (DWAs) in 89 First Nations communities south of $60^{\circ}$ north latitude (excluding British Columbia) due to confirmed or suspected microbiological or chemical contamination in the drinking water supply [19]. DWAs vary in cause, duration, and frequency, with some lasting a few days and others persisting for months or years as long-term advisories [20,21]. In 2009, Health Canada's review of DWAs in First Nation communities from 1995 to 2007 revealed that the median duration for a DWA was 39 days [22]. Furthermore, approximately 25\% of all DWAs were persistent, yielding a mean average duration of 343 days.

Indigenous communities have long adapted to the many drinking water challenges that are experienced in their communities [15]. Factors contributing to this adaptive capacity include human and technological innovation and a deep respect for, and relationship with, water [23]. For example, a number of First Nations in the prairie region have developed drinking water protection plans [15]. The aim of these plans is to identify any risks to their water supply, followed by mitigation actions to lessen identified risks. Indigenous ways of knowing and respect for water include a spiritual connection to water, recognition of water as a life form, and knowledge that water has many healing powers $[9,24,25]$. This research asks how Indigenous values of water may enhance and broaden the definition of water security. An Indigenous perspective on water security may provide a more nuanced and non-material understanding of the term while educating western science.

Water governance in Canada is highly decentralized, creating many challenges that hinder effective water management [1]. The responsibility for water management is shared by the federal, provincial, and municipal governments, and, in some instances, by the Territories and Indigenous governments under self-government agreements $[1,26,27]$. Jurisdictionally, First Nations fall within federal law irrespective of their provincial location [24,27]. As a result, a province may have a particular law protecting its watersheds, but if a First Nation community is located in that watershed, the community and its water bodies fall under federal law rather than provincial law [24]. These conditions have led to a string of governance gaps that include insufficient coordination among the various levels of government, poor data sharing across watershed groups, lack of coordination among government agencies, inadequate water monitoring, poor enforcement of water laws, and a general loss of accountability over water-related issues $[1,27,28]$.

At the level of federal jurisdiction, the government has specific jurisdiction over water that includes fisheries, transboundary waters, and lands reserved for First Nations, including First Nations drinking water. Four separate departments at this level also have authority over First Nations drinking water management: Health Canada, Indigenous Services Canada, Crown Indigenous Relations, and Environment and Climate Change Canada. The provincial governments in Canada have authority over water allocation and water resources on Provincial (Crown) lands. This provincial authority may be further delegated from the various provinces to municipal governments [29]. The constitutional division of authority over water in Canada across all levels of government has created inconsistent standards. Indigenous communities are particularly mired in a web of federal and provincial regulatory and jurisdictional fragmentation, adding to the daily challenges of delivering safe drinking water to community members $[24,27,30]$.

\section{Methodology}

A qualitative research approach using a semi-structured interview method was used for this study. The strength of this method is that it allows interviewers the flexibility to ask additional follow-up questions or to ask for clarification [31]. This approach allowed for a focus on the ways in which Indigenous participants understand, perceive, and interpret the term "water security". A total of twenty-one people from Indigenous communities in Saskatchewan were interviewed for this research. 


\subsection{Study Area}

The region that is now the province of Saskatchewan has been occupied by various Indigenous peoples of North America. The province is home to 103,205 First Nations, 52,450 Métis, and 290 Inuit [32]. Participants in this study were First Nations and Métis. There were no Inuit participants. Individuals that were interviewed represent Treaty Areas, 4, 5, and 6 in Saskatchewan (Figure 1).

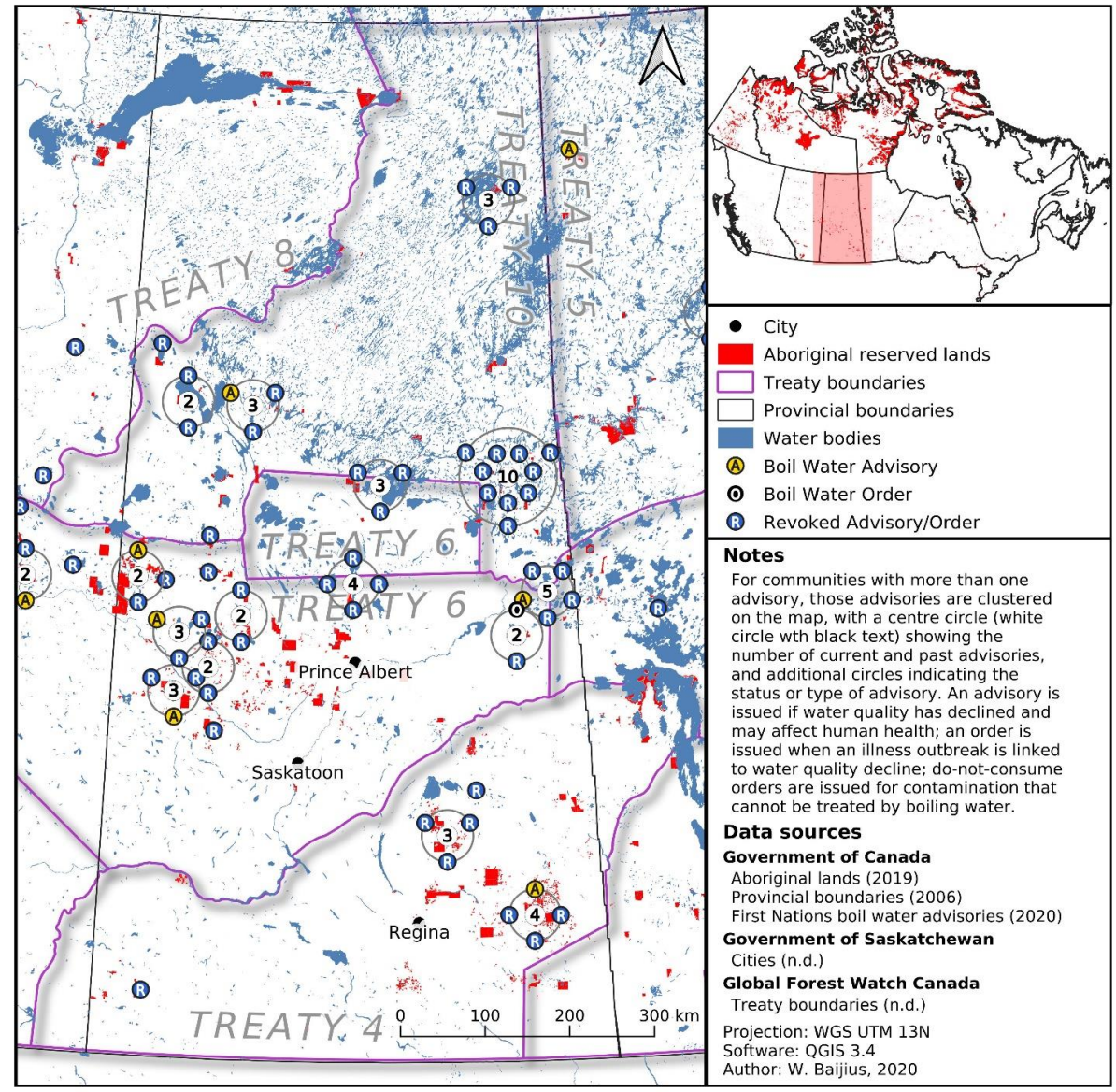

Figure 1. Treaty areas in Saskatchewan.

\subsection{Semi-Structured Interview Process}

The data collection method included interviews with selected participants. Participants were interviewed over a six-month period, from April to November 2017. There were a mix of face-to-face and telephone interviews using an interview guide. All interviews were voice recorded and transcribed verbatim by the lead author. The research design followed ethical protocols as defined by Ownership, Control, Access, and Possession (OCAP) principles [33]. OCAP is a principled research approach that ensures ethical and responsible engagement with Indigenous persons, including the management of data. This project was given the approval to proceed by the Research Ethics Office, University of Saskatchewan.

\subsection{Participant Selection}

The criteria for selection of interview participants was based on the following: interest in the research study; participant is a self-declared Indigenous adult; a resident of Saskatchewan; a person who has spent not less than fifteen (15) years in their community; and familiarity with water management issues in the community. These criteria were used to ensure that the selected participants had adequate knowledge of community water issues. Initial contact was by telephone survey. Additional participants 
were identified using the "snowball" technique through referrals from initial participants in order to expand the list of potential informants. Attempts were made for a gender balance of participants. However, just one-quarter of the interviewees were women. This may reflect the present dominance of men in the management of water. All participants have access to potable water at the household level from a community water system. In each community, water delivery is either piped water or trucked water from a water treatment plant. Boil water advisories, however, are a common occurrence within the study area. The communities are responsible for water system operation.

After each interview, the taped interviews were transcribed verbatim into a document using a naturalized transcription practice. The naturalized transcription process involves transcribing participant information in as much detail as possible [34]. This method was chosen because the more natural the conversation in the transcription, the more it preserves the participant's personal expression [33,34]. The transcripts of the interviews were sent back to participants for confirmation of accuracy. This approach allowed the participants to reflect on the answers they provided and to make alterations if desired.

\section{Results and Discussion}

\subsection{Indigenous Water Security}

All participants were first asked what the term "water security" means to them. In essence, we asked the Indigenous participants to provide comments on a western science term. In no instance was a participant confused by the term and unable to participate. All participants acknowledged that they had heard of the term "water security". Interestingly, no participant offered an Indigenous or alternative term for water security, although the interpretation of the term varied between participants. All participants were familiar with the term "water security" - this is likely the result of the participant's relative familiarity with current water issues and topics. Participants responded by noting that water security means having a reliable source of safe and abundant water with an emphasis on drinking water quality, land stewardship, water monitoring to prevent contamination and preservation of cultural identity (see Figure 2).

In response to the question of what water security means, one participant responded by stating, "Water security means essentially having a reliable source of water, water management, processes, and principles or infrastructural capacity services to provide safe reliable drinking water." The predominant explanation of water security, as understood by the participants, was the securing of water free from external contaminants to preserve a healthy flora and fauna. As one participant noted, "Water security means ... protecting the water at all costs from pollution, farmers, chemicals around any sort of watershed that has the potential to contaminate and lead into the streams, riverbeds, and lake beds (thus) protecting water quality for everyone. It is not just humans alone, but animals are also protected". Another participant noted, "Water security means if your water provides for the flora and fauna and it is not impacted by any unnatural source, and if it is, it is mitigated accordingly". Other participants understood water security in relation to the reliability of supply and abundance or quantity of water, focused on having enough water such that there would not be shortages at any point in the future. Another participant noted that the term referred to both water quality and quantity by stating that water security means "being able to have adequate access to a good supply of water and also a good quality with no barriers to access it". Another participant also noted that "it means having an acceptable water quality and quantity". Collectively, these "Indigenous" responses echo western science definitions of water security centered on the material meaning of the term, namely water availability, quality, and quantity. In the sections that follow, we describe new narratives around water security that offer additional and supplementary interpretations. 


\subsection{Water Security as Safety}

Those who explained the meaning of water security in terms of safety insisted that protecting water from all forms of contamination is necessary in order to provide healthy flora and fauna. This aligns with the definition put forward by Finlayson and Horwitz [35] who recognize that water security exists when humans and ecosystems are free from sources of harm to water. McGregor [25] further emphasized the importance of the connection between all our relations, human and non-human, including the earth, sun, and fish, with respect to Indigenous water knowledge and the ethics of water responsibility.

This group of participants had two main safety concerns. The first was the use of chemicals in the treatment of their drinking water. They explained that their water goes through a filtering system from the community's well, which is highly treated with strong chemicals and distributed to their homes. This, they explained, may be dangerous to their health. One Elder resorted to digging a well close to his house, using it as an alternative source of drinking water. He explained that the tap water connected to his home is used for other domestic purposes because he still tastes chemicals in the water and is concerned about his health. Although the Elder could not mention all the chemicals he tasted in the tap water, he was certain about the use of chlorine. This is mirrored by the results of others researching the health hazards of disinfection by-products. Studies show an increased risk of bladder and possibly colon cancer in people who consume chlorinated water for 35 years or more [36-38]. Also, Health Canada [39] report studies on humans found a link between long-term exposure to high levels of disinfection by-products, including a higher risk of developing cancer. These studies confirm the legitimacy of the concerns raised by Indigenous participants in this study regarding the safety of chlorinated drinking water. This signifies the fact that some Indigenous people from this group of participants are resorting to alternative, non-potable drinking water sources. These alternative sources may include sloughs, small creeks, or ponds with a higher risk of contamination rather than using potable water provided through community water treatment plants. There is a heightened risk of human illness from consuming untreated surface water, namely from E. coli, giardia, or cryptosporidium contamination.

\subsection{Land Stewardship}

Participants explained their understanding of water security in terms of land stewardship, specifically healthy household sanitation and solid waste management. As one participant noted, "Water security means to provide safe wastewater management to the residents of the community." Another participant said that it means "protecting our water supply by all means and also ensuring that in the event (that) we have a complete water breakdown on our First Nation that we are able to still provide water to our people so that they can still provide food, sanitation, and healthcare to their families". Solid waste and the condition of community landfills were noted to be a potential risk to local water supplies. Water security to many participants is directly connected to how humans treat the land. As one participant noted, "Water security means taking care of the land, we must be good stewards of the land if we want to keep our water healthy". This response is a stark reminder of the tragic water contamination events of Walkerton, ON, where 7 people died and 2500 people were made seriously ill in May 2000 [13].

The second safety concern was that of contamination from neighbouring land-use activities, specifically those activities connected to agricultural practices. Participants noted that some farmers use different types of fertilizers and other chemicals on their farmlands that pose a high degree of risk to source water, especially during the spring planting season. Participants also noted that their communities do not undertake frequent testing to ensure the safety of their water. A study by Corkal et al., [40] explains that surface and groundwater sources are at risk of contamination from agricultural practices. Several participants reported their concerns to federal and provincial agencies, but due to communication barriers between the community members and these agencies, it is difficult to know what action is being taken, if any. 
Participants from a northern Saskatchewan community explained their understanding of the term water security as the lack of reliable river water supply. During the interviews, the community participants raised concerns about how they have been negatively impacted by a hydropower facility built on the Saskatchewan River in the 1960s. The impact of reduces water flow into the Saskatchewan River Delta is a large reduction in the community's ability to trap animals and hunt, all traditional activities and local food sources. The findings align with an international study completed by Nguyen et al., [41], which reveals that dams have substantial impacts on the natural environment, namely, reduced downstream sediment deposition, impaired fish migration, reduced and altered timing of river flow, and flooded upland reservoir areas with associated impacts.

\subsection{Water Security as Monitoring}

The monitoring of water quality was another interpretation of the meaning of water security. In the words of one participant, "Water security means constant monitoring of the quality of water. Water managers should make us aware of what chemicals are coming into the river system. Water managers should monitor the river system to keep track of contaminants and get it treated immediately in order to provide water security to the community". Several participants noted that protecting water from contaminants leads to high water security. One participant stated, there is high water security when there is "access to water without too much chemicals to it (or) no contaminations". Another participant in agreement explained that, " ... when water is monitored and protected, it will be healthy for plants, crops, rivers, and lakes. Then there is high water security".

Cronmiller and Noble [42] explained that long-term, regional environmental monitoring that is joined with a shorter-term, more localized monitoring, when carried out under the right regulations, is foundational to understanding and effectively managing cumulative environmental effects, including factors that influence water security. These authors further explained that it is very common to see shifted priorities and competing mandates on projects due to lack of transparency, credibility, and lack of commitment by the agencies involved, which has led to a lot of uncertainties about the stability of institutions to support long-term environmental monitoring.

Numerous studies have shown that data obtained from long-term monitoring is often fragmented or insufficient in many regions in Canada, such that its usefulness in guiding decisions about cumulative environmental effects is compromised, which makes it unreliable [43,44]. Institutional arrangements to support project monitoring are important since its absence leads to failure to effectively protect the general environment $[42,44]$. Effective dialogue among Indigenous communities and stakeholders would greatly help to build trust and clear the way for successful project monitoring. Also, involving Indigenous people will help steer the decision-making process towards the protection of lands and all environmental resources that will help to reduce the water contamination issues.

Wilson et al., [44] recommend that focusing on an Indigenous community-based monitoring program that protects the waters and lands within Indigenous communities will help to generate reliable data that is useful for decision-making and governance rooted in an understanding of stewardship and responsibility. Indigenous community-based monitoring programs focus on Indigenous people's role as "knowledge holders" but does not limit them to just gathering data. However, it is a means of asserting sovereignty through the practice of stewardship and by gathering data that inform internal and external planning and decision-making [44]. Their research findings suggested that data quality and credibility, trust, legitimacy, and relevance to decision contexts are key to linking Indigenous community-based monitoring data to decision-making. Wilson et al., [44] recommend that Indigenous governments must take a lead role in community-based monitoring programs to build networks between and amongst Indigenous governments through bridging organizations. Indigenous community-based monitoring programs should be closely joined with Indigenous environmental governance strategies. This research indicates that involving Indigenous communities in monitoring their water quality will begin to address this persistent water problem. Data collected during the interviews revealed that participants are well aware of the fact that stakeholder stewardship and 
effective communication is important to effectively solve their water woes. This awareness might mean that this group of participants are willing to take over leading roles in community-based monitoring programs if they are given the opportunity to do so.

\subsection{Cultural Identity}

The previous three categories (safety, stewardship, and monitoring) align reasonably well with western science interpretations of water security in the water resources literature. Interestingly, other participants linked water security to cultural identity. It is to this category that we now focus our attention.

Approximately $20 \%$ of the respondents reported their understanding of the term water security as preserving cultural identities since preserving water for future generations means preserving various cultural ceremonies that surround water. Examples of cultural ceremonies are varied across different Indigenous groups in Canada. These cultural practices include, but are not limited to, the collection of water from specific locations to mix medicines, placing tobacco on melting river ice to rid any pollutants, and reference to women as water-keepers. As stated by one participant: "water security means understanding the entire water cycle and the relationships with human beings and all species. I think it's also understanding those interactions even though it may not be visible to our eye (and), in a sense, is our ability to protect our cultural identity using source water protection". Another participant said, "I think it means that the water we have today will be secure for the generations to come and use in the future". These participants were Cree and Métis in the Saskatchewan River Delta region, and, to this group, water security means preserving their identity through connection to the land and water. Cultural identity is the feeling of belonging to a group, and having a strong cultural identity is important to mental health and wellbeing $[25,45]$. An individual with a strong sense of their history and traditions will build a positive cultural identity for themselves. Cultural identity provides a sense of belonging and self-esteem, which supports personal wellbeing [25,45]. To this group of participants, preserving water for future generations means preserving cultural ceremonies that provide a sense of community and cultural belonging. Figure 2 (below) depicts interpretations of water security, as reported above.

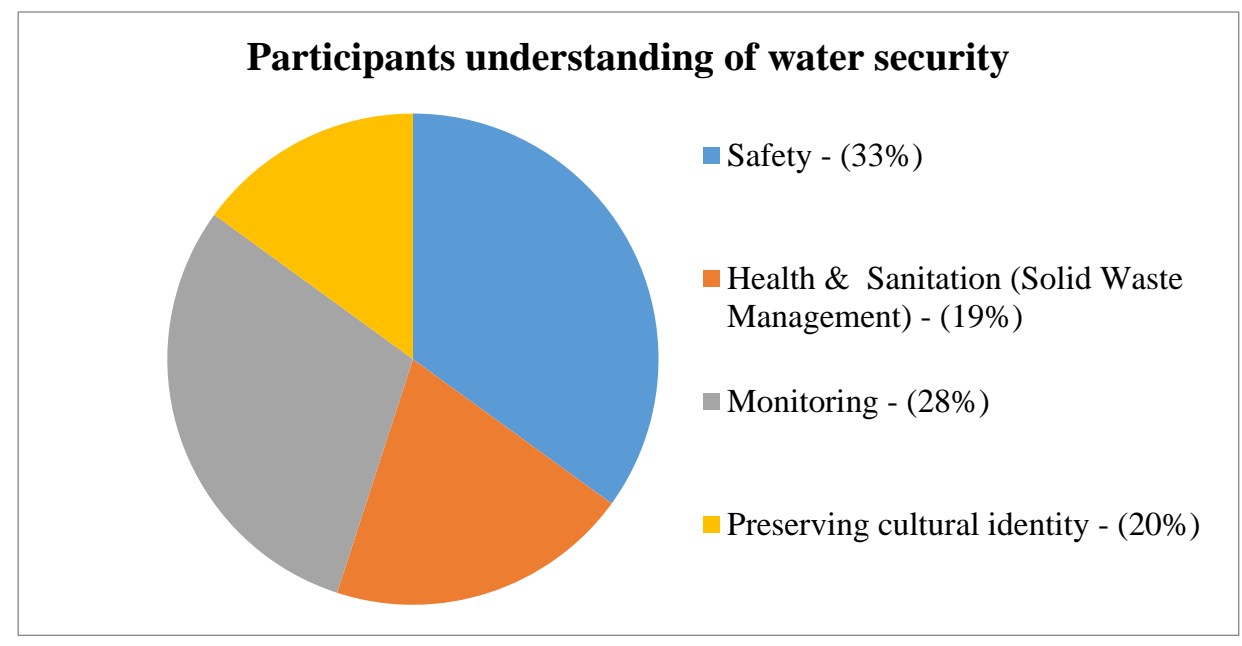

Figure 2. Interpretation of water security.

From these responses, it became clear that from an Indigenous perspective, water security had meaning beyond the material property of water (water quality, accessibility, and quantity). An "Indigenous perspective" introduces human values and relationships to water that includes respect for water and ethical decisions about water. The responses also identified those who feel that they have 
water security as well as those who feel a lack of water security. Participants noted that the more a community protects its water, the greater will be its water security.

\section{Indigenous Perspectives on Water Security}

Participants were asked what the term "water security" should mean. This provided an opportunity for the participant to share Indigenous traditional knowledge that they feel might add to the definition of "water security". It is important to note that the participants were not given any western scientific definition of the term water security or any established definition from the existing literature.

Participants often related water to a life form by explaining that the way we protect water, for example, by not polluting it and protecting it from various contaminants, will either greatly help or hinder our preservation of all life forms. A theme that emerged was that water has a female spirit. Participants explained that women are stewards of water, the water-keepers. Several participants mentioned that there is a strong relationship between water and women; hence women should be involved in making decisions concerning water. In the words of one participant, "The water spirit is a woman, and without women, no man or child will be alive. So women have to play a big role in water security. Women are warriors and they stand up for what is right. Without women, no one will exist". Both water and women give life, a consistent theme from all participants. Women, therefore, play a strong role in framing Indigenous water security.

Another theme that emerged was that we will have water security if humans can be better at protecting water. One participant explained that, "Indigenous beliefs order humans to be custodians and protectors of the land from pollution, and if humans fail to do so, then we will lose the purity of the land. Thus, our crops will not grow well, our rivers will lose the fish, and our general environment will be lost". He explained further that, "We will eventually reap whatever we sow in the land, so we will eventually lose everything that the land provides if we continue to pollute it". In that person's perspective, water security means learning from our ancestors by looking for alternative ways to reduce the amount of pollution we create through our human activities. Another participant stated, "Let us learn from our ancestors and look for alternatives to reduce pollution". Another participant made a link between people's individual behavior and the definition of water security by stating, "Those who pollute water are those who are least water-secure". These responses introduce a non-western science perspective on water security.

Other participants stressed the ethics of maintaining respect for water. They explained that when we show respect for water, we will then be able to make ethical decisions in favor of water. One participant stated that having water security means, "You care and respect water". For this reason, another theme materialized, stating that ethical decisions are important in water security.

While several participants referenced water security in the context of the utilitarian benefits of water, over 65 percent of participants spoke of a spiritual connection to water and the medicinal or healing properties of water. Others mentioned that water was a "source of strength" and a "universal foundation for all life". Still, others expressed that "water is a spirit, a sacred form".

One participant noted that water needed protection, "water provides for us, and there is a need to protect it to ensure its continuity". Another participant said, "I get my strength from water and I am a water protector." Participants noted that water has a significant role in Indigenous spirituality, such as "water has a spirit, and it connects the living to our ancestors". Another participant noted, "water has a memory, it has a thought, and it has a voice. Water is a senior spirit, and we are humble in its presence". Still, others reflected on the empowerment of water by stating, "water gives me strength, water gives me peace, so I respect it". Some gave expression to the utilitarian aspect of water, "I use water for daily domestic purposes, I relate to water through my field of work, water is my lifeline and a basic necessity". Participants indicated that there is a strong relationship between water and life. In the words of one participant, "Water means life, water is the fundamental resource in providing myself, my people, my community with the life-giving resources that ensure our way of life." Another 
participant stated, "Water means life; it cleanses our hearts, bodies, mind, spirit, and soul. Water is the most important thing next to air; there is no life without water; it keeps me alive".

All the participants affirmed that there is a strong relationship between water and Indigenous culture; hence, it is important to incorporate Indigenous values when making decisions about water. Doing so will ensure that Indigenous culture is respected. As stated by one participant, "There are ceremonies that do happen for certain family groups that include water. It is not public but more traditional; it is not something that is done by the entire community. I would like it to be a community thing". Cultural ceremonies include, but are certainly not limited to, open prayer and tobacco offerings, the use of water to heal the sick or infirm, and the bones of water creatures returned to the water to ensure continuity of the species. Indigenous cultural beliefs embrace water as a personal relation, as a brother and sister, and as such, must be protected, respected, and cared for. This cultural practice includes holding high respect for water as some water is angry, even dangerous [24]. One participant noted, "I know that First Nations peoples have a lot of their ceremonies based around water so when the water is contaminated it doesn't make the ceremonies as effective because water is revered by First Nations". Another participant further explained that some First Nations will put some celebrations on hold if they have any water contaminations reported, and the celebration only goes ahead after the contamination problem is resolved. Furthermore, another participant stated that, "We, as First Nations people, are the keepers of the land and keepers of the water and it's our duty to ensure that these things are not being abused, but sometimes too we fail, but this is because we are left out of the process. Nobody really actually cares to ask what First Nations people think, want, or need in terms of water security, for example". The participant further explained, "Unfortunately, First Nations are never involved nor consulted in decision-making processes in water management though we have a stronger connection to water. First Nations are only slightly involved when the situation is out of control".

A quarter of the participants indicated the importance of preserving natural water systems as a means toward water security. In the words of one participant, "Indigenous knowledge has been here for thousands of years, and this knowledge is based on the belief that we were put here to protect the land. This has been replaced by this new common knowledge to take the land and resources to generate wealth, and this is due to greed and corruption". This participant, when asked, further stated that we should go back to our basics where humans are supposed to protect the environment. Another participant noted, "Water security means protecting Mother Earth, protecting who we are, and protecting what we need to live". These participants further explained that if we fail to protect the environment, then we are no better than those who pollute it. Furthermore, another explained that "we used to have the trappers and the fishers and they had commercial fishing where they used to get lots of fish to sell, but we do not have them anymore. Our waters are so low, and we are losing our fish and beavers. We have one of the biggest deltas, but the animals are moving away because the delta is getting too shallow, and we are losing our way of life". This participant further explained that human activities are destroying the natural environment, and therefore we should reconsider the best ways to preserve it to bring back its natural state.

Several other participants mentioned ethical concerns related to water that they believe have effects on water security. In the words of one participant, "I think we need to consider the ethics of water. I think we don't make ethical decisions (about water)". The participant further noted that we should strive to make ethical decisions during negotiations that will affect water directly or indirectly in our communities. Perhaps most profound was the statement, "If you have water security, then it means you care and respect water".

Figure 3 consolidates those aspects of cultural identity as related to water security noted by the twenty-one participants of this study. This, we feel, is the main contribution to the current discourse on water security based on this study. From this, we see that there are multiple Indigenous cultural attributes attached to water security based on the results of this study. This helps provide both depth and structure to any Indigenous perspective on water security. 


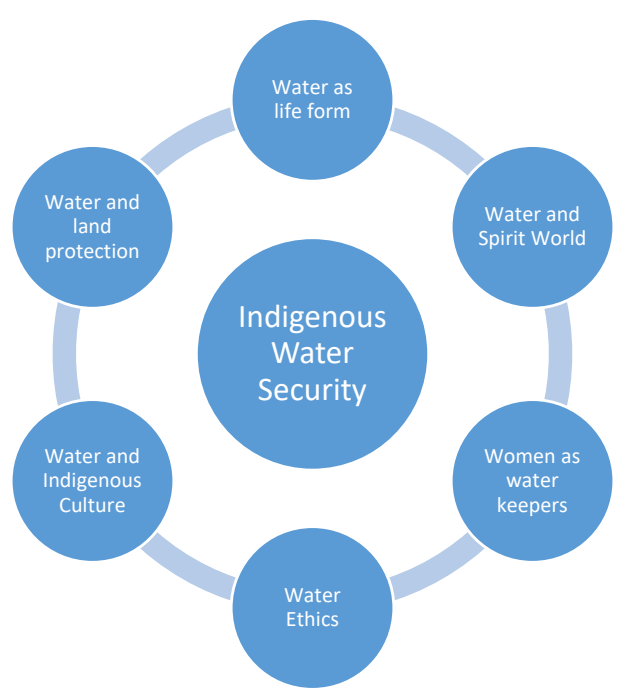

Figure 3. Indigenous water security.

The results from this research point toward two distinct perspectives on the meaning of water security. The first perspective aligns with western science that focuses on the material, physical properties of water. This utilitarian interpretation was initially offered among all the participants and linked to water availability, quality, and quantity.

The second perspective on water security was anchored in Indigenous traditional knowledge. Participants consistently expressed water security as something additional to the material, western science definition to include the medicinal and healing powers of water. Participants described water as a life form, a source of spiritual strength, and a center-piece for Indigenous culture. The participants viewed women as "keepers of the water" who should be directly involved in water management decisions. This perspective opened new interpretations of the term water security to include stewardship and care for water (and land) as a means of showing respect for ancestors, women, and community Elders. This second perspective opens new imaginaries of water security that includes forming respectful relationships with all forms of water, recognizing the medicinal and healing powers of clean water, cultural connectivity to water, and the importance of land stewardship to protect water. We view these multiple, sometimes overlapping Indigenous perspectives on water security not as competing or divergent perspectives from that of western science, but rather, as supplementary perspectives that will help awaken, inform and educate western science. Broadening the definition of water security to include Indigenous knowledge, particularly in Canada, will serve to improve water management and planning.

\section{Conclusions}

This research sought to gain a perspective on the meaning of water security from Indigenous peoples. Based on interview responses, the term water security encapsulates a meaning that transcends the material definition offered by conventional, western science. It became readily apparent during the interviews that two divergent perspectives on the term water security would evolve. These two perspectives represent the material, western science perspective, as well as an Indigenous perspective linked to customary and spiritual tradition. Rather than view these perspectives as divergent and competing, we propose that they be viewed as complementary and harmonizing. An Indigenous perspective on water security opens new and liberating imaginaries with a broadening of the water security discourse. Another outcome of this research is that there is no single Indigenous perspective on water security. Multiple perspectives came forward both on the understanding of water security and on the preferred interpretation of this term. As well, the Indigenous interpretation of water security contains both the western science interpretation but also the traditional knowledge interpretation. 
Admittedly, the findings of this research are based on a rather limited number of interview participants across a relatively small region of Canada. Opinions and perspectives on water security will vary between and among Indigenous populations in Canada. Yet, based on the consistency of participant responses, an Indigenous perspective on water security appears to expand the mainstream western science materiality definition to include relationships to land stewardship as well as cultural practices. This Indigenous perspective supports the human relational approach to water security not seen in western science. As an extension of this result, we see validation of Indigenous claims for greater control over water governance, including local decision-making, community-based monitoring, land stewardship, and preservation of cultural identity $[25,44]$. Applying these "Indigenous perspectives" on water security into more tangible water management actions, we hear the call for an Indigenous water governance model in Canada [44]. This research suggests that Indigenous communities would benefit from greater control over water management decisions, including monitoring, testing, and setting appropriate operational standards. This approach would be transformational for many Indigenous communities and a step towards greater sovereignty over planning and local land management.

In the current literature, water security is examined through the use of various approaches based on the scale of inquiry and the discipline under which it is assessed [46,47]. This research supports this notion but also extends the disciplinary application to Indigenous ways of knowing. Arguably, Indigenous people perceive the term "water security" from two worldviews. The western science world view was never contested in the interviews; in fact, it was supported. The material value and importance of water was never called into question. An Indigenous perspective is additive to the western science definition, serving to enrich and diversify the water security discourse. This research has contributed to the understanding that water security may also be a relational term, meaning different things to different people, with multiple meanings. Understanding the potential role of Indigenous perspectives on water security will serve to enhance the water security discourse, allowing for the inclusion of additional perspectives and an extension of the human relational approach to water security more generally [46]. How this may apply to, and be transformational for, Indigenous water governance is worthy of greater exploration.

Author Contributions: Conceptualization, O.A. and R.P.; methodology, O.A.; validation, R.P.; investigation, O.A.; writing-review and editing, R.P. and W.B.; visualization, W.B.; supervision, R.P.; project administration, W.B. and R.P. All authors have read and agreed to the published version of the manuscript.

Funding: This research was partially funded by the National Sciences and Engineering Research Council CREATE for Water Security program at the University of Saskatchewan.

Acknowledgments: The authors are grateful to the many participants in this study who took the time to share their knowledge on the subject of water security. Any errors or omissions are the sole responsibility of the authors.

Conflicts of Interest: The authors declare no personal circumstances or interest that may be perceived as inappropriately influencing the representation or interpretation of reported research results. The funders had no role in the design of the study; in the collection, analyses, or interpretation of data; in the writing of the manuscript; or in the decision to publish the results.

\section{References}

1. Bakker, K.; Cook, C. Water Governance in Canada: Innovation and Fragmentation. Int. J. Water Resour. D 2011, 27, 275-289. [CrossRef]

2. Cook, C.; Bakker, K. Water Security: Critical Analysis of Emerging Trends and Definitions. In Handbook on Water Security, 1st ed.; Pahl-Wostl, C., Bhaduri, A., Gupta, J., Eds.; Edward Elgar Publishing: Cheltenham, UK, 2016; pp. 19-37.

3. Global Water Partnership. Towards Water Security: A Framework for Action; Global Water Partnership: Stockholm, Sweden, 2000.

4. De Fraiture, C.; Molden, D.; Wichelns, D. Investing in Water for Food, Ecosystems, and Livelihoods: An Overview of the Comprehensive Assessment of Water Management in Agriculture. Agric. Water Manag. 2010, 97, 495-501. [CrossRef] 
5. Grey, D.; Sadoff, C.W. Sink or Swim? Water Security for Growth and Development. Water Policy 2007, 9, 545-571. [CrossRef]

6. Witter, S.G.; Whiteford, S. Water Security: The Issues and Policy Challenges. Int. Rev. Comp. 1999, 11, 1-25.

7. Kaplowitz, M.D.; Witter, S.G. Identifying Water Security Issues at the Local Level: The Case Study of Michigan's Red Cedar River. Water Int. 2002, 27, 379-386. [CrossRef]

8. Gerlak, A.K.; Mukhtarov, F. ‘Ways of Knowing' Water: Integrated Water Resources Management and Water Security as Complementary Discourses. Int. Environ. Agreem. Politics Law Econ. 2015, 15, 257-272. [CrossRef]

9. Longboat, S. First Nations Water Security: Security for Mother Earth. Can. Woman Stud. 2015, 30, 6-13.

10. Sarkar, A.; Hanrahan, M.; Hudson, A. Water insecurity in Canadian Indigenous communities: Some Inconvenient Truths. Rural Remote Health 2015, 15, 3354.

11. Wilson, N.J.; Harris, L.M.; Joseph-Rear, A.; Beaumont, J.; Satterfield, T. Water is Medicine: Reimagining Water Security through Tr'ondëk Hwëch'in Relationships to Treated and Traditional Water Sources in Yukon, Canada. Water 2019, 11, 624. [CrossRef]

12. Eggertson, L. Investigative Report: 1766 Boil-Water Advisories Now in Place across Canada. Can. Med. Assoc. J. 2008, 178, 1261-1263. [CrossRef]

13. Patrick, R. Uneven Access to Safe Drinking Water for First Nations in Canada: Connecting Health and Place through Source Water Protection. Health Place 2011, 17, 386-389. [CrossRef] [PubMed]

14. Hanrahan, M.; Sarkar, A.; Hudson, A. Water Insecurity in Indigenous Canada: A Community-Based Inter-Disciplinary Approach. Water Qual. Res. J. Can. 2016, 51, 270-281. [CrossRef]

15. Patrick, R.; Machial, L.; Quinney, K.; Quinney, L. Lessons Learned Through Community-Engaged Planning. Int. Indig. Policy J. 2017, 8, 1-17. [CrossRef]

16. Arsenault, R.; Diver, S.; McGregor, D.; Witham, A.; Bourassa, C. Shifting the Framework of Canadian Water Governance through Indigenous Research Methods: Acknowledging the Past with an Eye on the Future. Water 2018, 10, 49. [CrossRef]

17. von der Porten, S.; de Loë, R.C. Water Challenges and Solutions in First Nations Communities; Water Policy Governance Group: Waterloo, ON, Canada, 2010; pp. 1-15. Available online: https://uwaterloo.ca/water-policy-and-governance-group/sites/ca.water-policy-and-governancegroup/files/uploads/files/vonderporten_and_deloe_2010_0.pdf (accessed on 23 December 2019).

18. Plummer, R.; de Grosbois, D.; de Loë, R.; Velaniškis, J. Probing the Integration of Land Use and Watershed Planning in a Shifting Governance Regime. Water Resour. Res. 2011, 47, 1-13. [CrossRef]

19. First Nations and Inuit Health: Drinking Water Advisories. Available online: http://www.hc-sc.gc.ca/fniahspnia/promotion/public-publique/water-eau-eng.php (accessed on 15 May 2017).

20. Health Canada. Drinking Water Advisories in First Nations Communities in Canada-A National Overview 1995-2007; Government of Canada: Ottawa, ON, Canada, 2009. Available online: http://www.hc-sc.gc. ca/fniahspnia/pubs/promotion/_environ/2009_water-qualit-eau-canada/index-eng.php (accessed on 5 May 2017).

21. Basdeo, M.; Bharadwaj, L. Beyond Physical: Social Dimensions of the Water Crisis on Canada's First Nations and Considerations for Governance. Indig. Policy J. 2013, 23, 1-14.

22. First Nations and Inuit Health. Drinking Water Advisories in First Nations Communities in Canada-A National Overview 1995-2007. Available online: https:/www.canada.ca/content/dam/hc-sc/migration/hc-sc/ fniah-spnia/alt_formats/pdf/pubs/promotion/environ/2009_water-qualit-eau-canada/2009_water-qualiteau-canada-eng.pdf (accessed on 23 December 2019).

23. Baijius, W.; Patrick, R. Planning Around Reserves: Probing the Inclusion of First Nations in Saskatchewan's Watershed Planning Framework. Int. Indig. Policy J. 2019, 10, 1-27. [CrossRef]

24. Phare, M.-A.S. Denying the Source: The Crisis of First Nations Water Rights; Rocky Mountain Books Ltd.: Victoria, BC, Canada, 2009; pp. 1-101.

25. McGregor, D. Traditional Knowledge and Water Governance: The ethic of responsibility. Alternative 2014, 10, 493-507. [CrossRef]

26. Norman, E.; Bakker, K.; Cook, C.; Dunn, G.; Allen, D. Water Security: A Primer; University of British Columbia-Program on Water Governance: Vancouver, BC, Canada, 2010; Available online: http: //watergovernance.sites.olt.ubc.ca/files/2010/04/WaterSecurityPrimer20101.pdf (accessed on 1 March 2020). 
27. Bradford, L.; Ovsenek, N.; Bharadwaj, L. Indigenizing Water Governance in Canada. In Water Policy and Governance in Canada; Renzetti, S., Dupont, D.P., Eds.; Springer International: Cham, Switzerland, 2017; pp. 269-298. [CrossRef]

28. Patrick, R. Indigenous Source Water Protection: Lessons for Watershed Planning in Canada. In Reclaiming Indigenous Planning; Walker, R., Natcher, D., Jojola, T., Eds.; McGill-Queen's University Press: Montreal, QC, Canada, 2013; pp. 376-395.

29. Norman, E.; Bakker, K.; Cook, C. Introduction to the Themed Section: Water Governance and the Politics of Scale. Water Altern. 2012, 5, 52-61.

30. Baijius, W.; Patrick, R. “We Don't Drink the Water Here”: The Reproduction of Undrinkable Water for First Nations in Canada. Water 2019, 11, 1079. [CrossRef]

31. Oliver, D.G.; Mason, T.L.; Serovich, J.M. Constraints and Opportunities with Interview Transcription: Towards Reflection in Qualitative Research. Soc. Forces 2005, 84, 1273-1289. [CrossRef] [PubMed]

32. Aboriginal Peoples: Facts Sheet for Saskatchewan (Statistics Canada). Available online: http://www.statcan. gc.ca/pub/89-656-x/89-656-x2016009-eng.htm (accessed on 23 December 2019).

33. Schnarch, B. Ownership, control, access, and possession (OCAP) or self-determination applied to research: A critical analysis of contemporary First Nations research and some options for First Nations communities. J. Aborig. Health 2004, 1, 80-95.

34. Roulston, K. Analysing Interviews. In The SAGE Handbook of Qualitative Data Analysis; Flick, U., Ed.; SAGE Publications: London, UK, 2014; pp. 297-312. [CrossRef]

35. Finlayson, C.M.; Horwitz, P. Wetlands as Settings for Human Health-The Benefits and the Paradox. In Wetlands and Human Health; Finlayson, C.M., Horwitz, P., Weinstein, P., Eds.; Springer: Dordrecht, The Netherlands, 2015; pp. 1-13. [CrossRef]

36. Mills, C.J.; Bull, R.J.; Cantor, K.P.; Reif, J.; Hrudey, S.E.; Huston, P. Health Risks of Drinking Water Chlorination By-Products: Report of an Expert Working Group. Chronic Dis. Can. 1998, 19, 91-102. [PubMed]

37. Levallois, P.; Gingras, S.; Marcoux, S.; Legay, C.; Catto, C.; Rodriguez, M.; Tardif, R. Maternal Exposure to Drinking-Water Chlorination By-Products and Small-For-Gestational-Age Neonates. Epidemiology 2012, 23, 267-276. [CrossRef] [PubMed]

38. Cheung, P.C. A Historical Review of the Benefits and Hypothetical Risks of Disinfecting Drinking Water by Chlorination. J. Environ. Ecol. 2017, 8, 73-151. [CrossRef]

39. Drinking Water Chlorination: The Risks of Chlorination By-Products (Health Canada). Available online: https://www.canada.ca/en/health-canada/services/healthy-living/your-health/environment/drinkingwater-chlorination.html (accessed on 21 August 2017).

40. Corkal, D.R.; Diaz, H.; Sauchyn, D. Changing Roles in Canadian Water Management: A Case Study of Agriculture and Water in Canada's South Saskatchewan River Basin. Int. J. Water Resour. D 2011, 27, 647-664. [CrossRef]

41. Nguyen, H.T.; Pham, T.H.; Bruyn, L.L.D. Impact of Hydroelectric Dam Development and Resettlement on the Natural and Social Capital of Rural Livelihoods in Bo Hon Village in Central Vietnam. Sustainability 2017, 9, 1422. [CrossRef]

42. Cronmiller, J.; Noble, B. The Discontinuity of Environmental Effects Monitoring in the Lower Athabasca region of Alberta, Canada: Institutional Challenges to Long-Term Monitoring and Cumulative Effects Management. Environ. Rev. 2018, 26, 169-180. [CrossRef]

43. World Wildlife Fund Canada. Watershed Reports. A National Assessment of Canada's Freshwater; World Wildlife Fund Canada: Toronto, ON, Canada, 2017; Available online: http://assets.wwf.ca/downloads/WWF_ Watershed_Reports_Summit_FINAL_web.pdf (accessed on 23 December 2019).

44. Wilson, N.J.; Mutter, E.; Inkster, J.; Satterfield, T. Community-Based Monitoring as the Practice of Indigenous Governance: A Case Study of Indigenous-Led Water Quality Monitoring in the Yukon River Basin. J. Environ. Manag. 2018, 210, 290-298. [CrossRef]

45. Lavalley, G. Aboriginal Traditional Knowledge and Source Water Protection: First Nations' Views on Taking Care of Water; Chiefs of Ontario: Toronto, ON, Canada, 2006. 
46. Jepson, W.; Budds, J.; Eichelberger, L.; Harris, L.; Norman, E.; O’Reilly, K.; Pearson, A.; Shah, S.; Shinn, J.; Staddon, C.; et al. Advancing Human Capabilities for Water Security: A Relational Approach. Water Secur. 2017, 1, 46-52. [CrossRef]

47. Wutich, A.; Ragsdale, K. Water Insecurity and Emotional Distress: Coping with Supply, Access, and Seasonal Variability of Water in a Bolivian Squatter Settlement. Soc. Sci. Med. 2008, 67, 2116-2125. [CrossRef] [PubMed]

(C) 2020 by the authors. Licensee MDPI, Basel, Switzerland. This article is an open access article distributed under the terms and conditions of the Creative Commons Attribution (CC BY) license (http://creativecommons.org/licenses/by/4.0/). 